\title{
Accuracy and precision in sampling hyporheic fauna
}

\author{
Brian G. Fraser and D. Dudley Williams
}

\begin{abstract}
A series of interstitial faunal samples was taken from a riffle in the Speed River, southern Ontario, Canada, to compare the field performance of four hyporheic samplers: the standpipe, colonization, and freeze corers and a pump sampler. Each of the samplers proved useful for collecting purely qualitative data, but statistical differences in some of the measured quantitative parameters were identified. The colonization corer significantly underestimated invertebrate density at each of the depths tested (20,40, and $60 \mathrm{~cm}$ below the surface of the river bed). Taxonomic richness did not differ among the samplers. A sampling bias in the pump sampling method was identified in terms of both the proportion of insect larvae captured and the mean chironomid body size and is probably the result of a filtering effect of the interstices. Sampling precision estimates of density, richness, and organismal size ranged from 20 to $40 \%$, but no pattern among the four samplers for any of the measures was observed. We conclude that, whereas the standpipe and freeze coring methods most effectively characterize the hyporheos, one of the other methods might prove acceptable under specific field circumstances or under certain practical constraints.
\end{abstract}

\begin{abstract}
Résumé : Une série d'échantillons de la faune interstitielle a été prélevée dans un rapide de la rivière Speed, dans le sud de l'Ontario, Canada, pour comparer le rendement sur le terrain de quatre échantillonneurs hyporhéiques : la colonne montante, les carotteuses de colonization et avec congélation et un échantillonneur à pompe. Chacun des échantillonneurs s'est révélé utile pour prélever des données purement qualitatives, mais des différences statistiquement significatives ont été décelées dans le cas de certains des paramètres quantitatifs mesurés. La carotteuse de colonization a sous-estimé de manière significative la densité des invertébrés à chacune des profondeurs testées (20,40 et $60 \mathrm{~cm}$ sous la surface du lit de la rivière). La richesse taxinomique n'a pas différé d'un échantillonneur à l'autre. Un biais d'échantillonnage a été observé dans le cas de l'échantillonneur à pompe en termes de proportion des larves d'insectes capturées et de taille moyenne des chironomidés capturées, et cette situation est sans doute attribuable à l'effet de filtration des interstices. La précision des estimations par échantillonnage de la densité, de la richesse et de la taille des organismes a varié entre 20 et $40 \%$, mais aucune tendance n'a été observée parmi les quatre échantillonneurs pour l'une ou l'autre des mesures effectuées. Nous concluons que si les méthodes de la colonne montante et du carottage avec congélation ont permis de caractériser le plus efficacement l'hyporhéos, une des autres méthodes pourrait se révéler acceptable dans des conditions particulières ou lorsqu'il faut respecter certaines contraintes pratiques.

[Traduit par la Rédaction]
\end{abstract}

\section{Introduction}

Recognition of the hyporheic zone (the interstitial habitat bordered by the surface water of a stream or river above and by true groundwater below) as an integral component of running waters has expanded the spatial extent of lotic ecosystems to include the vertical dimension (see Hynes 1980; Ward 1989). Yet, as hyporheic research progresses, it is prudent to acknowledge that a number of fundamental problems persist in obtaining accurate and precise quantitative and qualitative data on the hyporheos. Assessment of the relative collection efficiencies of different sampling devices, presently lacking, is essential if hyporheic research is to reach the experimental phase (Palmer 1993).

The numerous hyporheic sampling devices that have been

Received July 3, 1996. Accepted October 7, 1996.

J13536

B.G. Fraser ${ }^{1}$ and D.D. Williams. Surface and Groundwater Ecology Group, University of Toronto at Scarborough, 1265 Military Trail, Scarborough, ON M1C 1A4, Canada.

Author to whom all correspondence should be addressed. e-mail: bfraser@scar.utoronto.ca used throughout the last few decades can be loosely assigned to four categories (Table 1). Although many of these designs have met with some success, no single sampler has been applied in all field situations, and there is disagreement as to which sampling techniques are most efficient (see reviews in Williams 1984 and Bretschko and Klemens 1986). In this study, we compared the field performance of hyporheic faunal samplers from each of the four categories. Specifically, for each sampler we assessed, at different sediment depths, accuracy and precision in terms of total invertebrate density, taxon richness, and invertebrate size distribution.

\section{Study area}

The Speed River, located in southern Ontario, flows through gently undulating hills, drumlin fields, glacial spillways, and swampy depressions (Chapman and Putnam 1966) with an average gradient of $2 \mathrm{~m} / \mathrm{km}$ (Ontario Department of Planning and Development 1953). Approximately $80 \%$ of the watershed is used for mixed farming, although floodplains of the upper course are largely wooded, reforested, or maintained as rough pasture (Bishop and Hynes 1969). The main sampling area, the Rowan Farm study site $\left(43^{\circ} 43^{\prime} 54^{\prime \prime} \mathrm{N}, 80^{\circ} 16^{\prime} 24^{\prime \prime} \mathrm{W}\right), \sim 5 \mathrm{~km}$ from the river's spring source, consists of a $40 \mathrm{~m}$ long riffle. 
Table 1. Summary of hyporheic sampler types

\begin{tabular}{lcc}
\hline Sampler type & Method of collection & References \\
\hline (1) Nonfrozen sediment cores & $\begin{array}{c}\text { Simultaneous extraction of interstitial water, sediments, and } \\
\text { fauna }\end{array}$ & Williams and Hynes 1974, Palmer 1993 \\
(2) Artificial substrates & $\begin{array}{c}\text { Retrieval of device filled with representative or standard } \\
\text { artificial substrate after suitable period of exposure to }\end{array}$ & Hynes 1974, Boulton et al. 1991, Panek 1991 \\
& colonization by hyporheos & \\
(3) Frozen sediment cores & Extraction of sediment core frozen to the outside of a standpipe & Stocker and Williams 1972, Pugsley and \\
(4) Pumps or bailers & following delivery of a coolant (e.g., liquid $\mathrm{N}_{2}$, liquid $\left.\mathrm{CO}_{2}\right)$ & Hynes 1983, Bretschko and Klemens 1986 \\
& Extraction of interstitial water and fauna from permanent or & Bou and Rouch 1967, Husmann 1971, \\
& temporary standpipes or wells & Stanford and Ward 1988
\end{tabular}

River width varies from 4 to $6 \mathrm{~m}$ and water depth varies from 7 to $12 \mathrm{~cm}$ during baseflow conditions (mean weekly baseflow discharge approximately $3 \mathrm{~m}^{3} / \mathrm{s}$ ) to $70 \mathrm{~cm}$ or more at the height of spring runoff. To a depth of $30 \mathrm{~cm}$, the substrate is composed primarily of gravels $(<10 \mathrm{~cm}$ diameter) intermixed with silts and sands together with a few larger dolomite slabs. Below $30 \mathrm{~cm}$, substrate heterogeneity is low and substrate composition is dominated by medium and fine sand (Stocker and Williams 1972).

\section{Materials and methods}

Between July 1 and July 21, 1994, six replicate samples from each of three depths $(20,40$, and $60 \mathrm{~cm}$ below the surface of the river bed) were obtained at random locations along the length of the study riffle with each of four sampling devices: the standpipe corer (Williams and Hynes 1974); the freeze corer (after Stocker and Williams 1972); the colonization corer (Fraser et al. 1996); and a pump sampler (after Bou and Rouch 1967). All samples were preserved and stained in the field using a mixture of $10 \%$ formalin and Rose Bengal. In the laboratory, all samples were washed through a $53 \mu \mathrm{m}$ mesh net and hand sorted under 10-40× magnification with the aid of a dissecting microscope. To facilitate comparison, all invertebrate densities were converted to and subsequently reported as standard densities per unit sediment volume (number of animals per litre sediment).

The colonization corer (Fig. 1) combines aspects of an artificial substrate sampler (after a prototype by Panek 1991) and a bundle piezometer (Cherry 1983) and is described in detail by Fraser et al. (1996). To sample fauna, sediment-filled acrylic colonization sleeves were inserted into the external standpipes. The sediment in the sleeves was mixed to specifications that mimicked the vertical sediment particle distribution of the river bed (obtained using the method of Stocker and Williams 1972). Following a colonization period of 9 weeks, the acrylic sleeves were removed from the corer with the aid of a tripod and winch. Both benthic (Mason et al. 1973; Lamberti and Resh 1985) and hyporheic (Coleman and Hynes 1970; Boulton et al. 1991) substrate colonization studies indicate that this is ample time for levels of both organic matter and fauna to return to natural levels. As the sleeves were withdrawn, they were wrapped in plastic film to prevent the loss of invertebrates. The sleeves were immediately cut into $20-\mathrm{cm}$ sections (volume $125 \mathrm{~mL}$ ) and the sediment from each section was transferred to plastic sample jars. Colonization corer samples included sediment $\pm 10 \mathrm{~cm}$ from the depth indicated (e.g., the 20 -cm sample ranged from 10 to $30 \mathrm{~cm}$ ).

The standpipe corer (Fig. 1) ( see Williams and Hynes 1974; Williams 1981) was driven into the river bed to the appropriate depth $(20,40$, or $60 \mathrm{~cm}$ below the surface of the river bed) with a manual post driver. The corer was twisted clockwise until the inner sampling chamber was filled (volume $25 \mathrm{~mL}$ ). The requisite number of turns needed to fill the chamber was determined by practice but was typically 7 to 10 . Before removal, the chamber was locked in the closed position to prevent the loss of animals. Chamber contents were transferred to plastic sample jars. Standpipe corer samples included sediment $\pm 5 \mathrm{~cm}$ from the depth indicated.

The freeze corer (Fig. 1) (see Stocker and Williams 1972; Bretschko and Klemens 1986) and two insulated copper rods were driven into the substratum with the post driver. Using a portable generator, an electric field $(630 \mathrm{~V}, 60 \mathrm{~Hz}$ AC) was maintained for $10 \mathrm{~min}$ between the copper rods to paralyze the fauna. Bretschko and Klemens (1986) suggest that in situ electropositioning prevents animals from evading the cold front as the liquid nitrogen is delivered and is likely to keep the entire fauna immobilized for at least $15 \mathrm{~min}$ (Klemens 1983). After disconnecting the electrical field, a metal funnel was placed in the top of the standpipe and liquid nitrogen $(8-10 \mathrm{~kg})$ was delivered over a 10-min period. The frozen sediment core was extracted with the aid of a tripod and winch and then portioned into $10-\mathrm{cm}$ segments. The dimensions of each section, along with its shape, were carefully recorded to accurately determine each section's volume. Frozen core sample volumes varied but generally comprised sediment $\pm 10 \mathrm{~cm}$ from the depth indicated.

The pump sampler used (Fig. 1) was essentially the same as those designed by Husmann (1971) and Bou and Rouch (1967); however, an electric pump (rather than a manual pumping device) was used to facilitate sample collection. Replicate 1-L samples of interstitial material (water, fine-grained sediments, and organic matter) were obtained and subsequently transferred to plastic sample jars. The actual sediment volume from which the 1-L samples were collected was estimated based on previously determined porosity values of the sediment at this site (Stocker and Williams 1972).

\section{Numerical analyses}

Density and taxonomic richness data were compared using a one-way ANOVA (SPSS Inc. 1995, version 6.1.3) to detect among sampling technique differences. A post-hoc Tukey-HSD test (SPSS Inc. 1995, version 6.1.3) was used to identify differences among individual treatments. Log-transformed density data were homoscedastic $\left(F_{\max }\right.$; $P>0.05$ ) and normally distributed (Wilk-Shapiro).

A comparison of the mean size (body length) of chironomid larvae (the most common taxon encountered) was performed using a oneway ANOVA and a post-hoc Tukey-HSD test to evaluate potential size-capture bias of any of the sampling methods. To facilitate this comparison, all chironomids captured were grouped according to both sampling technique and depth (nine groups in total). Body length (distance between the anterior of the head and the posterior of the last abdominal segment; Meyer 1989) was measured from a random subsample $(n=25)$ from each group. Individuals were selected with the aid of a random numbers table (Morris and Rolph 1981).

The effectiveness of the samplers at describing the hyporheic community at the Speed River was assessed in two ways. First, we qualitatively compared all of the taxa (at the gross taxonomic level, e.g., order) captured with each of the sampling methods. Secondly, the proportions of insect larvae obtained with each of the four samplers at each depth sampled were compared with a one-way ANOVA followed by a Tukey-HSD test. Proportion data were arcsine transformed to fulfil the assumptions of ANOVA. 
Fig. 1. Diagrammatic representation of the four devices used to collect hyporheic samples: standpipe corer; freeze corer; colonization corer; and the pump sampler. Scale provided is approximate and applies to all samplers. The pump sampler used in this study is essentially the same as shown (after Husmann 1971), although unlike in the diagram, an electric pumping device was used to collect samples. W, weighted sleeve used for pounding the samplers into the stream bed.

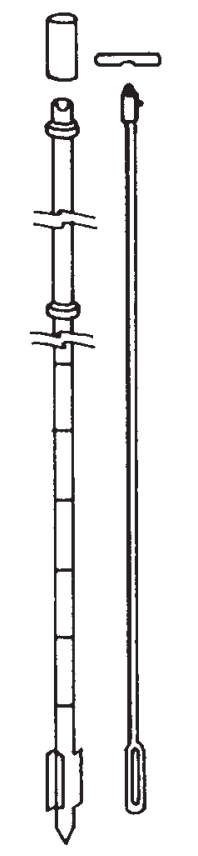

Standpipe Corer

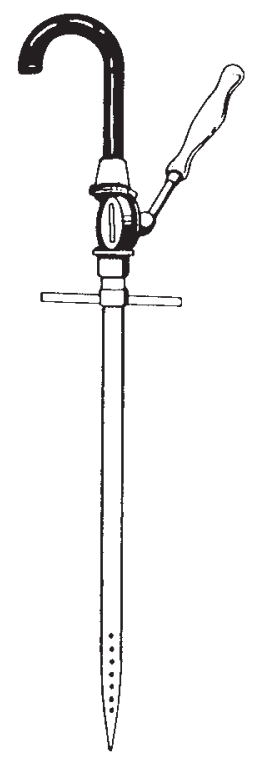

Pump Sampler

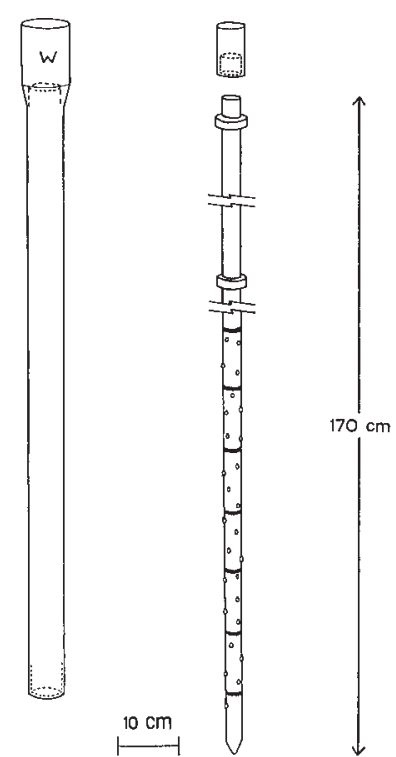

Freeze Corer

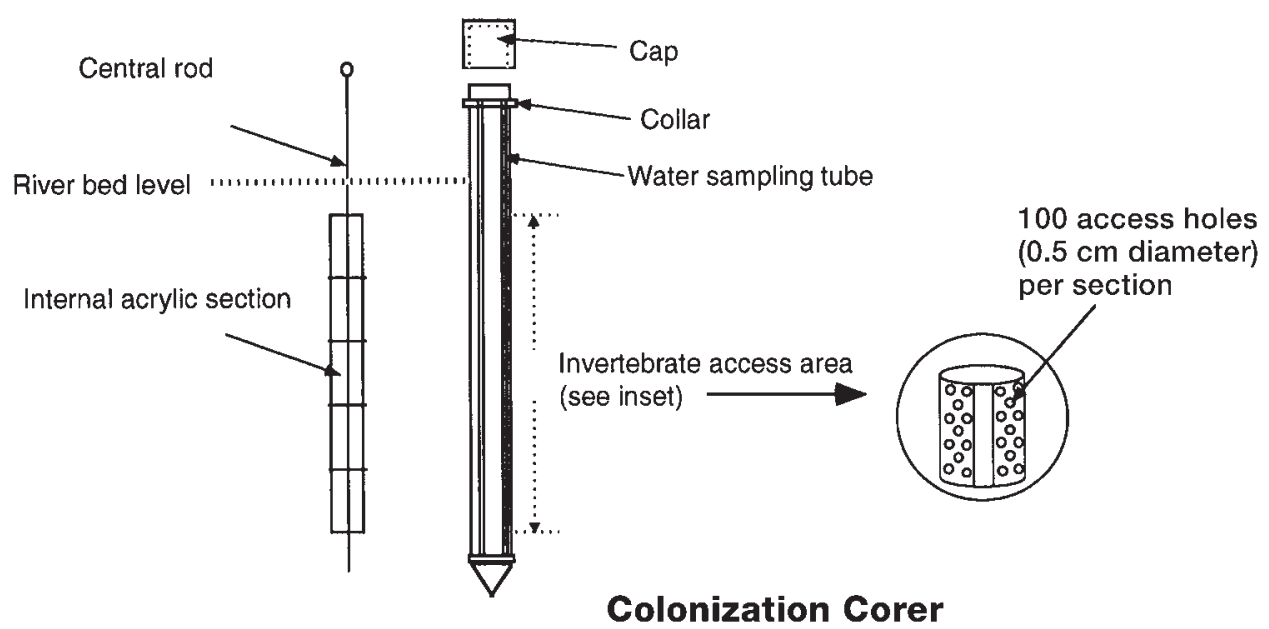

The coefficient of variation (CV; standard deviation expressed as the percentage of the mean; Sokal and Rohlf 1981) was used to measure precision among the four sampling devices for the density, taxon richness, and chironomid size data.

Separate studies using the standpipe corer (Williams 1981) and the freeze corer following in situ electropositioning (Bretschko 1985; Bretschko and Klemens 1986) concluded that each of the methods provided accurate quantitative estimates of hyporheic community structure (e.g., density). We therefore made the a priori assumption that the numbers derived from these methods (i.e., density, taxon richness, size, and community measures) would be the accuracy standard with which the colonization corer and pump sampler would be compared.

\section{Results}

A significant difference was detected among density estimates derived with the four samplers at each of the three depths tested (Fig. 2A, Table 2). In each case, the Tukey-HSD test identified only the colonization corer estimates as different $(P<0.05)$ from those obtained with the other methods. In general, greater than $40-50 \%$ of all animals captured were found at a depth of $20 \mathrm{~cm}$. This pattern was evident for each of the samplers and has been noted both at this site (e.g., Williams and Hynes 1974; Godbout and Hynes 1982) and others (e.g., Williams 1989; Bretschko 1992). Total density estimates for the standpipe and 
Fig. 2. Comparison of hyporheic faunal samples at three depths taken with four devices at the Speed River: (A) invertebrate density (number of animals per litre of substrate) and (B) its coefficient of variation (CV; \%); (C) taxonomic richness (gross taxonomic level) and (D) its CV; (E) proportion of insect larvae captured (\%); and (F) mean chironomid size (mm) and (G) its CV.
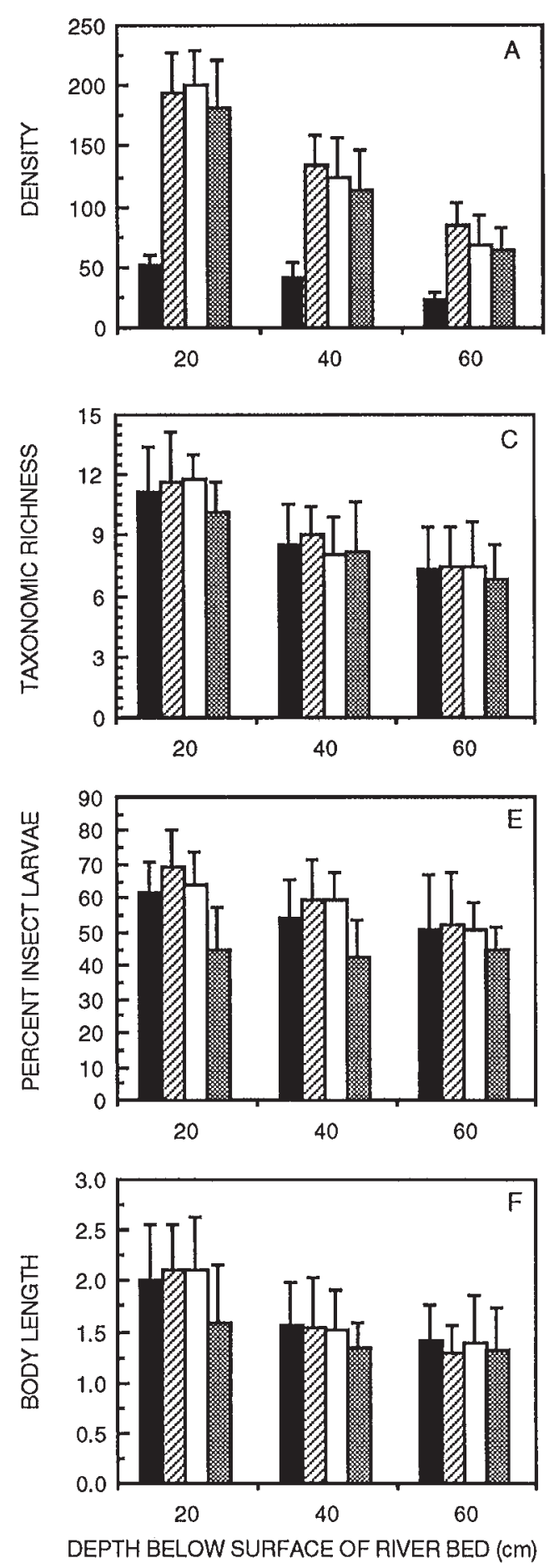

freeze corers and the pump sampler were similar to those reported previously at this site during the same time of year (Williams and Hynes 1974; Fraser 1995).

The potential capture bias of any of the hyporheic samplers for a particular taxon or group of taxa was determined by comparing mean richness among the samplers at the three test depths (Fig. 2C). No differences in taxonomic richness among
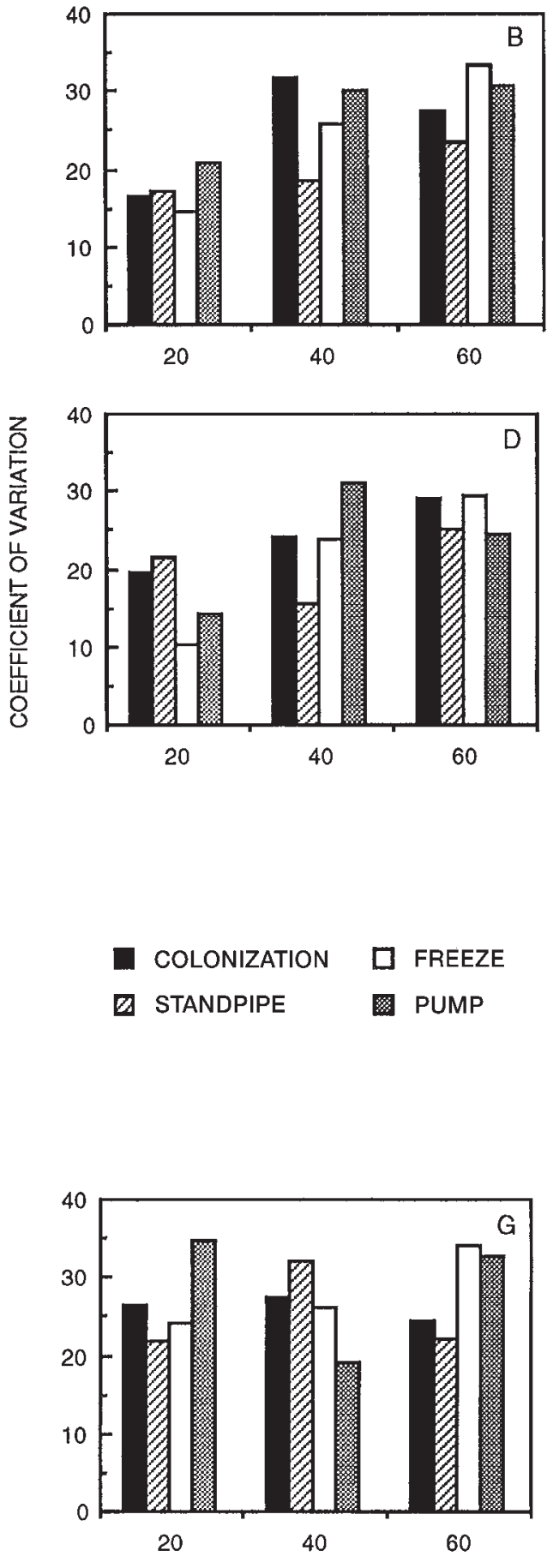

DEPTH BELOW SURFACE OF RIVER BED $(\mathrm{cm})$ the samplers were detected (Table 2). Richness was greatest at $20 \mathrm{~cm}$ and decreased with increasing depth; the same pattern was evident with each of the samplers tested.

Taxonomic capture bias was assessed also by comparing qualitative and quantitative aspects of hyporheic community structure. Qualitatively, all of the samplers captured individuals from greater than $90 \%$ of the same taxa. All samplers captured 
individuals from the Nematoda, Mollusca, Ostracoda, Copepoda, Acari, Ephemeroptera, Plecoptera, Trichoptera, Coleoptera, and Diptera. However, Tardigrada were captured only with the freeze and pump samplers; Cladocera with the standpipe, colonization, and pump samplers; and Amphipoda with the standpipe, colonization, and freeze samplers. For a quantitative analysis, the proportion of larvae of all insect taxa present in samples obtained with each of the samplers for the three depths was compared (Fig. 2E). Only at a depth of $20 \mathrm{~cm}$ was a difference among samplers detected $(P<0.05)$. The proportion of insect larvae obtained with the pump sampler was different from the other three methods (Tukey-HSD test, $P<$ $0.05)$. Although no significant differences were detected at depths of 40 or $60 \mathrm{~cm}$, the proportion of insect larvae obtained with the pump sampler was generally less than that obtained with either the standpipe, colonization, or freeze corers.

Chironomid body size decreased with increasing depth for all of the samplers, although to a lesser extent for the pump sampler (Fig. 2F). A significant difference in size was detected among the samplers at a depth of $20 \mathrm{~cm}$ (Table 2) with the pump sampler collecting smaller larvae than the other three methods (Tukey-HSD test).

For all of the samplers tested and all of the measures compared (density, richness and size), the CV was generally between 20 and $40 \%$ and increased with depth (Figs. 2B, 2D, and $2 \mathrm{G}$ ). No pattern was obvious among samplers, and none had consistently high $\mathrm{CV}$ values across all of the measures evaluated nor for any of the measures individually.

\section{Discussion}

\section{Accuracy and precision}

In a strict sense, only with sampling devices that remove an exact, representative portion of habitat is it possible to obtain absolute measures. Of the four samplers tested, only the freeze corer meets this criterion. Previous field and laboratory tests of the accuracy of the freeze coring technique, following in situ positioning, have concluded that the device provides accurate quantitative measures (Pugsley and Hynes 1983; Bretschko 1985; Bretschko and Klemens 1986). To our knowledge of the four sampler types tested in this study, only the standpipe corer has been previously evaluated quantitatively. Williams (1981) compared density estimates and the range of taxa captured with the standpipe corer to similar measures from buckets of substrate from which the cores were taken. The corer produced a mean error estimate of total numbers of only $19 \%$, and virtually all of the most common taxa in the substrates sampled were captured. Both Elliott (1977) and Cummins (1975) suggest that this level of accuracy is acceptable in estimating benthic densities, and perhaps the same is applicable to the hyporheos.

Given the conclusions of these previous tests, we initially assumed that both the freeze and standpipe corers would provide accurate estimates for the variety of parameters we measured. No statistical differences were detected between the freeze and standpipe corers for any of the measured variables at any of the three test depths. As it is unlikely that both devices would exhibit the same capture bias in each case we believe that our a priori assumption was a reasonable one.

All four of the samplers tested would suffice for collecting
Table 2. One-way ANOVA summaries for density, richness, size, and hyporheic community structure (proportion of insect larvae) comparisons among the four sampling methods at each of the three test depths.

\begin{tabular}{lcrr}
\hline Measure & Depth & \multicolumn{1}{c}{$F$} & \multicolumn{1}{c}{$P$} \\
\hline Density & 20 & 28.9044 & $<0.0001$ \\
& 40 & 12.2996 & 0.0001 \\
Taxonomic richness & 60 & 10.1102 & 0.0003 \\
& 20 & 0.7685 & 0.5251 \\
Chironomid size & 40 & 0.2373 & 0.8693 \\
& 60 & 0.1255 & 0.9439 \\
Proportion of insect larvae captured & 20 & 5.2686 & 0.0021 \\
& 40 & 1.6674 & 0.1792 \\
& 60 & 0.7409 & 0.5303 \\
& 40 & 4.5807 & 0.0134 \\
& 60 & 0.3740 & 0.0622 \\
\hline
\end{tabular}

purely qualitative (e.g., species list) data; however, this is not the case for quantitative measures. The colonization corer consistently underestimated total invertebrate density. We suggest that this could be a result of loss of animals upon retrieval of the inner, substrate-filled acrylic sleeves. Alternatively, it is possible that the introduced substrate lacked the particle packing, arrangement, and (or) organic matter content of the natural interstitial sediments and therefore was colonized by a novel invertebrate community. Whereas there has been extensive work done on the colonization of artificial benthic substrates (see review in Rosenberg and Resh 1982), to date little is known about the physical habitat requirements of the hyporheos. It may be that the information presently available regarding the colonization of sediments may be inaccurate for hyporheic substrate colonization samplers. More investigation of subsurface colonization dynamics therefore is clearly required.

The pump sampler we tested was capture selective in terms of both insect larvae and organism size. This bias was most conspicuous at a depth of $20 \mathrm{~cm}$, coincidentally the depth at which the largest proportion of insect larvae and the biggest animals (i.e., near-emergence late-instar individuals) were found. We suggest that this bias is the result of a filtering effect of the interstices. Larger animals and animals with a body morphology that make it possible for them to grasp on to substrate particles are likely to resist the suction of the pump and are therefore likely to be underrepresented during sampling.

High levels of precision in the data would be desirable, for example, in manipulative studies where some control condition is compared with an experimental treatment. In this situation it would be advantageous to use a sampling device that had a reliably high level of precision for the measure of interest. None of our samplers outperformed the others for all measures or for any measure individually, with respect to precision. It would appear, therefore, that any one of the samplers would be equally appropriate to generate an acceptable level of precision.

\section{Comments on the performance and applicability of hyporheic fauna samplers}

Despite their similar qualitative performance, it is unlikely that any one device would be useful in all field situations or for all 
purposes. For example, the freeze core method can provide a useful description of the invertebrates and substrate especially when escape of invertebrates in response to physical disturbance or temperature gradients has been minimized by in situ positioning. Yet, in certain situations, it may not be a practical or appropriate technique. Removing a series of frozen cores from a stream bed destroys the habitat for an undetermined, but extended, period. Although the disturbed sediments would be recolonized and organic matter levels would probably return to normal conditions, the potentially permanent alteration of interstitial flow dynamics and vertical sediment and interstitial pore space configurations may render the freeze corer unsuitable for monitoring localized temporal patterns or for experimental work. As these two research areas appear to be the focus of present and future hyporheic studies (Palmer 1993; Jones and Holmes 1996), it is likely that the applicability of freeze corers may now be somewhat limited, especially as there are numerous logistical constraints that hinder their use including ( $i$ ) the equipment is heavy and cumbersome; (ii) retrieval of the core can be an arduous task, especially for samples taken deep in the bed; and (iii) freeze coring will not work well in a river with buried boulders. (In fact, none of the devices works well in rivers with buried boulders as they all initially require some degree of manual insertion into the bed.)

Advantages and disadvantages associated with the use of the colonization corer are probably similar to those common to all artificial substrates used to sample freshwater benthic macroinvertebrates (see review by Rosenberg and Resh 1982). Possible problems include $(i)$ a loss of information on natural variation in the spatial distribution of animals (Rosenberg and Resh 1982), although this can be addressed by filling the acrylic sleeves with simulated natural mixtures of sediment; (ii) a potential capture bias for particularly active taxa because artificial substrates largely measure the relative activity of taxa within the community, although no evidence of this was noted with the colonization corer (activity of the hyporheos may be related to ambient temperatures and therefore there may be a seasonal component to the selection bias); and (iii) the underestimate of total animal density probably as a result of the loss of animals during substrate retrieval. To remedy this latter problem Coleman and Hynes (1970) used a mesh bag in between the outer and inner sediment-filled pots buried in the stream bed to capture animals that would have been otherwise lost during retrieval. This was not incorporated into the design of the colonization corer because we thought it more prudent to have as small a space as possible $(<3 \mathrm{~mm})$ rather than having a large gap between the inner and outer portions (as in the case with the Coleman and Hynes device). A large gap between the natural and artificial substrates has the potential to create novel access routes for the movement of both interstitial organisms and water.

However, the colonization corer also has a number of advantages. Firstly, once the outer steel standpipes have been installed in the bed, sampling be can completed with minimum habitat disturbance. Secondly, substrate characteristics (e.g., vertical sediment profile, organic matter quantity or quality, standardized vs. representative substrate) can be manipulated to investigate hyporheic colonization dynamics. The ability to control or mimic substrate characteristics makes the colonization corer useful for sampling a wide range of substrate types. Thirdly, the design of the colonization corer makes it possible to collect not only faunal samples, but also the water sampling tubes fixed to the outer standpipe permit continuous monitoring of the hydrogeological and chemical features of the system. The colonization corer, therefore, has the potential to be an effective hyporheic sampling device, especially for experimental manipulations in the field.

The standpipe corer was effective for characterizing all aspects of the hyporheic community: it is a versatile sampler that provides instantaneous samples with minimum disturbance and can be easily modified to collect interstitial water. The two most obvious disadvantages to the standpipe corer are both mechanical: $(i)$ it is very labour intensive in that it may take up to several minutes of continuous sledge hammering to insert the standpipe into deeper parts of the bed; and (ii) any large substrate particles, and probably their associated fauna, will not be sampled.

Although pump samplers have been and are currently being used extensively in hyporheic studies, our data indicated that all types of insect larvae and particularly late-instar chironomids, were underrepresented in samples obtained with this technique. Pump samplers are not without some merit, for example, they can be permanently installed to facilitate continuous monitoring with minimal physical effort and long-term habitat disturbance. Permanently installed standpipes or wells can be used also as piezometers and, therefore, can facilitate collection of hydrogeologic and (or) water chemistry data.

We conclude that the ideal hyporheic sampler still evades researchers and indeed may not be attainable. Nevertheless, within the range of samplers examined in this study, protocols exist that allow acceptable levels of sediment description, water sampling and faunal characterization to be made, although not through one apparatus alone.

\section{Acknowledgements}

We are grateful to the landowners, the MacKenzie family, for not only providing us with unlimited access to the field site, but also for their interest in our work. We thank Allan Wong and Marilyn Smith for help with the field work and Drs. Nancy Williams and Ian Hogg for useful comments on the manuscript. Dr. Maurice Lock contributed both brain and muscle power to sampling design in "the early years." This project was funded by a grant from the Natural Sciences and Engineering Research Council of Canada to D.D.W.

\section{References}

Bishop, J.E., and Hynes, H.B.N. 1969. Upstream movements of the benthic invertebrates in the Speed River, Ontario. J. Fish. Res. Board Can. 26: 279-298.

Bou, C., and Rouch, R. 1967. Un nouveau champ de researches sur la faune aquatique souterraine. C. R. Hebd. Séances Acad. Sci. Ser. III, 265: 369-370.

Boulton, A.J., Stibbe, S.E., Grimm N.B., and Fisher, S.G. 1991. Invertebrate recolonization of small patches of defaunated hyporheic sediments in a Sonoran Desert stream. Freshwater Biol. 26: $267-277$.

Bretschko, G. 1985. Quantitative sampling of the fauna of gravel streams. Verh. Int. Ver. Theor. Angew. Limnol. 22: 2949-2052.

Bretschko, G. 1992. Differentiation between epigeic and hypogeic fauna in gravel streams. Regul. Rivers Res. Manage. 7: 17-22.

Bretschko, G., and Klemens, W.E. 1986. Quantitative methods and 
aspects in the study of the interstitial fauna of running waters. Stygologia, 2: 297-316.

Chapman, L.J., and Putnam, D.F. 1966. The physiography of southern Ontario. University of Toronto Press, Toronto, Ont.

Cherry, J.A. 1983. Piezometers and other permanently installed devices for groundwater monitoring. In Proceedings of the Petroleum Association for Conservation of the Canadian Environment, May 2-5, 1982, Ottawa, Ont. Petroleum Association for Conservation of the Canadian Environment, Ottawa, Ont. pp. IV1-IV39.

Coleman, M.J., and Hynes, H.B.N. 1970. The vertical distribution of the invertebrate fauna in the bed of a stream. Limnol. Oceanogr. 15: $31-40$.

Cummins, K.W. 1975. Macroinvertebrates. In River ecology. Edited by B.A. Whitton. University of California Press, Berkeley, Calif. pp. $170-199$.

Elliott, J.M. 1977. Some methods for the statistical analysis of samples of benthic invertebrates. Sci. Publ. No. 25. 2nd ed. Freshwater Biological Association, Ambleside, U.K.

Fraser, B.G. 1995. Boundary flux of the hyporheic zone as determined by biotic and abiotic factors. M.Sc. thesis, University of Toronto, Toronto, Ont.

Fraser, B.G., Williams, D.D., and Howard, K.W.F. 1996. Monitoring biotic and abiotic processes across the hyporheic/groundwater interface. Hydrogeol. J. 4: 36-50.

Godbout, L., and Hynes, H.B.N. 1982. The three dimensional distribution of the fauna in a single riffle in a stream in Ontario. Hydrobiologia, 97: 87-96.

Husmann, S. 1971. Eine neue Methode zur Entnahme von Interstitialwasser aus subaquatischen Lockergesteinen. Arch. Hydrobiol. 68: $519-527$.

Hynes, H.B.N. 1980. Groundwater and stream ecology. Hydrobiologia, 100: 93-99.

Jones, J.B., Jr. and Holmes, R.M. 1996. Surface-subsurface interactions in stream ecosystems. Trends Ecol. Evol. 11: 239-242.

Klemens, W. 1983. Zur problematik quantitativer probennahmen in bettsedimenten von Schotterbachen. Jahresberieht Biologische Station Lunz, Austria, 6: 25-47.

Lamberti, G.A., and Resh, V.H. 1985. Comparability of introduced tiles and natural substrates for sampling lotic bacteria, algae and macroinvertebrates. Freshwater Biol. 15: 21-30.

Mason, W.T., Jr., Weber, C.I., Lewis, P.A., and Julian, E.C. 1973. Factors affecting the performance of basket and multiplate macroinvertebrate samplers. Freshwater Biol. 3: 409-436.
Meyer, E. 1989. The relationship between body length parameters and dry mass in running water invertebrates. Arch. Hydrobiol. 17: 191-203.

Morris, C.N., and Rolph, J.E. 1981. Introduction to data analysis and statistical inference. Prentice-Hall, Inc. Englewood Cliffs, N.J.

Ontario Department of Planning and Development. 1953. Speed Valley Conservation Report. Ontario Department of Planning and Development, Toronto, Ont.

Palmer, M.A. 1993. Experimentation in the hyporheic zone: challenges and prospectus. J. North Am. Benthol. Soc. 12: 84-93.

Panek, K.L.J. 1991. Migrations of the macrozoobenthos within the bedsediments of a gravel stream (Ritrodat-Lunz study area, Austria). Verh. Int. Ver. Theor. Angew. Limnol. 24: 1944-1947.

Pugsley, C.W., and Hynes, H.B.N. 1983. A modified freeze-core technique to quantify the distribution of fauna in stony streambeds. Can. J. Fish Aquat. Sci. 40: 637-643.

Rosenberg, D.A., and Resh, V.H. 1982. The use of artificial substrates in the study of freshwater benthic macroinvertebrates. In Artificial substrates. Edited by J. Cairns. Ann Arbor Science Publishers, Inc., Ann Arbor, Mich. pp. 175-235.

Sokal, R.R., and Rohlf, F.J. 1981. Biometry. 2nd ed. W.H. Freeman $\&$ Co., New York.

SPSS Inc. 1995. SPSS ${ }^{\circledR}$ for Windows ${ }^{\mathrm{TM}}$. Base system user's guide, release 6.0. SPSS Inc., Chicago, Ill.

Stocker, Z.S.J., and Williams, D.D. 1972. A freezing core method for describing the vertical distribution of sediments in a stream bed. Limnol. Oceanogr. 17: 136-139.

Ward, J.V. 1989. The four-dimensional nature of lotic ecosystems. J. North Am. Benthol. Soc. 8: 2-8.

Williams, D.D. 1981. Evaluation of a standpipe corer for sampling aquatic interstitial biotopes. Hydrobiologia, 83: 257-260.

Williams, D.D. 1984. The hyporheic zone as a habitat for aquatic insects and associated arthropods. In The ecology of aquatic insects. Edited by V.H. Resh and D.M. Rosenberg. Praeger Publishers, New York. pp. 430-455.

Williams, D.D. 1989. Towards a biological and chemical definition of the hyporheic zone in two Canadian rivers. Freshwater Biol. 22: 189-208.

Williams, D.D., and Hynes, H.B.N. 1974. The occurrence of benthos deep in the substratum of a stream. Freshwater Biol. 4: 233-256. 